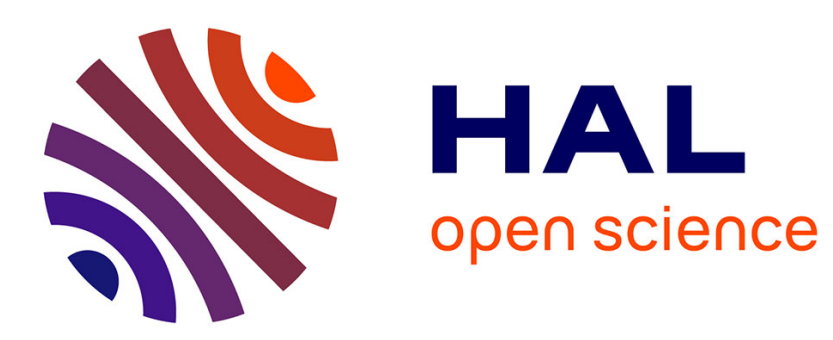

\title{
Salt leaching using powder (SLUP) process for glass/chitosan scaffold elaboration for biomaterial applications
}

Jibed Refifi, Hassane Oudadesse, O. Merdrignac-Conanec, Hafed El Feki, Bertrand Lefeuvre

\section{To cite this version:}

Jibed Refifi, Hassane Oudadesse, O. Merdrignac-Conanec, Hafed El Feki, Bertrand Lefeuvre. Salt leaching using powder (SLUP) process for glass/chitosan scaffold elaboration for biomaterial applications. Journal of The Australian Ceramic Society, 2020, 56 (3), pp.1167-1178. 10.1007/s41779-02000460-6 . hal-02797031

HAL Id: hal-02797031

https://hal-univ-rennes1.archives-ouvertes.fr/hal-02797031

Submitted on 17 Jun 2020

HAL is a multi-disciplinary open access archive for the deposit and dissemination of scientific research documents, whether they are published or not. The documents may come from teaching and research institutions in France or abroad, or from public or private research centers.
L'archive ouverte pluridisciplinaire HAL, est destinée au dépôt et à la diffusion de documents scientifiques de niveau recherche, publiés ou non, émanant des établissements d'enseignement et de recherche français ou étrangers, des laboratoires publics ou privés. 


\title{
Salt leaching using powder (SLUP) process for glass/chitosan scaffold
}

\section{elaboration for biomaterial applications}

Q1 5

6

\author{
Jihen Refifi ${ }^{1,2} \cdot$ Hassane Oudadesse $^{1} \cdot$ O. Merdrignac-Conanec ${ }^{1} \cdot$ Hafed El Feki $^{2} \cdot$ Bertrand Lefeuvre $^{1}$
}

1 CNRS, ISCR-UMR 6226, University Rennes, F-35000 Rennes, France

2 Laboratory of Materials Sciences and Environment, University of Sfax, 3038 Sfax, Tunisia

\begin{abstract}
Tissue engineering has emerged as an alternative approach to create bone tissue by growing cells on 3D scaffolding. The aim of this study was to synthesize a composite glass/chitosan (BG-CH) by using new salt leaching using powder (SLUP) process in order to control the porosity rate and then the chemical reactivity of the final product. SLUP process consists on the cavity creation with desired pore sizes. It does not require heat treatment. This process is based on washing out the $\mathrm{NaCl}$ particles used for that. It is due to its high solubility in aqueous media. This work focuses on the elaboration, physicochemical, and chemical reactivity studies of pure bioactive glass and bioactive glass associated with chitosan. A range of composite scaffolds with different bioactive glass/chitosan contents has been synthesized. $\mathrm{NaCl}$ with a distinct range size was used with the aim of optimizing the pore network. Obtained results show that the specific surface area and pore volume increase with increasing of chitosan and porogen content. The same observations for pore volume were registered. The obtained scaffolds had high porosity (90\%) with good pore connectivity. SEM images revealed strong dependence of sizes and shapes of pores on the salt/composite ratios.
\end{abstract}

Keywords Bioactive glass $\cdot$ Chitosan $\cdot$ Biomaterial $\cdot$ Salt leaching using powder $\cdot$ Porosity

\section{Introduction}

Large, nonhealing bone defects caused by trauma, tumor resection, or disease pose major clinical and socioeconomic problems. In situations with significant bone loss, bone grafts are used to fill the defect bone and promote bone tissue formation $[1,2]$. More than 500,000 bone-grafting procedures are performed every year [3]. This number is projected to increase steadily due to population aging and correspondingly rising incidence of degenerative musculoskeletal diseases. At present, there is no ideal treatment for large bone defects. Bone allografts could be interesting; however, their clinical utility is limited by the risk of disease transmission and high cost [4-6]. To overcome the shortcomings of bone grafting, much research effort is focused on the development of

hassane.oudadesse@univ-rennes1.fr synthetic bone scaffolds as bone graft substitutes. They are widely regarded to be one of the key items along with cells and a dynamic environment for regeneration of damaged tissue [7-9]. Scaffolds are three-dimensional porous structures that act as templates for in situ bone regeneration. The successful design of a bone scaffold needs to incorporate both biological physicochemical and mechanical considerations [10]. The basic biological requirement of any bone scaffold is osteoconductivity, i.e. the ability to support the attachment of bone cells and to provide an interconnected pore structure through which cell migration and vessel formation can take place. To satisfy these conditions, scaffolds need wellinterconnected pores and suitable porosity $[11,12]$ and large specific surface and uniform pore distribution with a degradation or resorption rate that the tissue replacement needs [13]; also, it needs to be biocompatible and biodegradable. Scaffolds are desired to minimize the amount of implanted material and to increase the specific surface area for cell attachment, a vibrant environment for regeneration of damaged tissue and tissue in growth $[14,15]$. Cells are developed on a biodegradable porous scaffold in which the tissue is forming and growing; the scaffold gradually degrades.

For this reason, several methods have been developed to prepare porous scaffolds with well pore interconnectedness 
and suitable porosity, uniform pore distribution, and various surface areas to allow sufficient transport of nutrients and facilitate multicellular processes. Such properties affect not only cell survival, signaling, growth, propagation, and reorganization, but also play major roles in influencing cell shape modeling and gene expressions that relate to cell growth and the preservation of native phenotypes both in vivo and in vitro [16].The representative traditional methods are solvent casting [17-19], phase separation [20, 21], gas foaming [22, 23], freeze drying, and, what we found nowadays, the $3 \mathrm{D}$ plotter method [24]. The manufacturing of 3D scaffold with guaranteed interconnectivity is not reported except 3D-plotter technique [25]. However, 3D-plotter technique has some demerits, which are the necessity of expensive equipment and the requirement of long manufacturing time. In this regard, salt leaching presented the easier and viable pore-forming method for preparing tissue-engineering scaffolds. By leaching of soluble particulates or porogens, the resulting scaffolds with feasible pore size, good pore interconnectivity, and high porosity can be obtained [26, 27]. A large number of biopolymers are available. For instance, both natural polymers, including hyaluronic acid (HyA), collagen, alginate, and fibrin, and synthetic polymers as poly (ethylene glycol) (PEG), poly(lactic acid) (PLA), poly(glycolic acid) (PGA), poly (lactidecoglycolide) (PLGA) have been successfully used for production of scaffold for various tissue targets $[28,29]$. In the present work, we report a modified particulate leaching method to fabricate 46S6-chitosan composite scaffolds with improved pore interconnectivity by mixing salt porogen particles with composite powder granules.

Chitosan is a biodegradable, nontoxic, natural biopolymer. It has been widely investigated for biomedical applications and tissue engineering. Chitosan is known to have various biological activities including immune enhancing effects, antitumoral, antifungal, and antimicrobial activities. Chitosan is degraded by enzymatic hydrolysis; however, its tensile strength and elasticity are not suitable for some biomedical applications such as wound dressing and skin tissue replacement. Chitosan joined to other polymers opened a window of research for altering or tailoring the property of interest. We have reported a novel fabrication method of hybrid biomaterial Bioglass (46S6)-chitosan scaffolds fabrication by salt leaching using powder (SLUP) as described in "Materials and methods."

\section{Materials and methods}

\section{Preparation of bioactive glass}

First, the bioactive glass 46S6 has been prepared from sodium metasilicate $\left(\mathrm{Na}_{2} \mathrm{SiO}_{3}\right)$, silicon oxide $\left(\mathrm{SiO}_{2}\right)$, calcium metasilicate $\left(\mathrm{CaSiO}_{3}\right)$, and sodium metaphosphate
$\left(\mathrm{Na}_{3} \mathrm{P}_{3} \mathrm{O}_{9}\right)$. It is composed of $46 \%$ of $\mathrm{SiO}_{2}, 24 \%$ of $\mathrm{CaO}$, $24 \%$ of $\mathrm{Na}_{2} \mathrm{O}$, and $6 \%$ of $\mathrm{P}_{2} \mathrm{O}_{5}$ as detailed in our previous works [30]. The premixed mixtures were melted in platinum crucibles that were placed in an electric furnace. The first rise of temperature rate was $10{ }^{\circ} \mathrm{C} \mathrm{min}{ }^{-1}$, and it was held at $900{ }^{\circ} \mathrm{C}$ for $1 \mathrm{~h}$ to achieve the decarbonation of all products. The second rise of temperature rate was $20^{\circ} \mathrm{C} \mathrm{min}{ }^{-1}$, and it was held to $1350{ }^{\circ} \mathrm{C}$ for $3 \mathrm{~h}$. The samples have been casted in preheated molds, in order to form cylinders of $13 \mathrm{~mm}$ in diameter and annealed at $565^{\circ} \mathrm{C}$ for $4 \mathrm{~h}$ near the glass transition temperature of each glass. After grinding it, $46 \mathrm{~S} 6$ become ready to use for the synthesis of two types of scaffolds:

- Scaffold synthesized by salt leaching using powder method that is called "SLUPS"

- Scaffold synthesized by lyophilization process that is called "LS"

\section{Preparation of SLUP scaffolds}

SLUP scaffolds have been synthesized using salt leaching using powder process. The adopted process is described in Fig. 1. The fabrication of those scaffolds can be summed up as follows:

1) The first step has consisted to dissolve chitosan powder, with a medium molecular weight; in acetic acid solution $1 \% \mathrm{v} / \mathrm{v}$. Moderate heating and stirring can promote the complete dissolution.

2) Then, the sieved $46 \mathrm{~S} 6$ powder should be added in fixed 137 amount to the chitosan solution to obtain the desired 138 weight fraction; the system is continuously stirred to ame- 139 liorate the glass powder dispersion.

3) Among several porogens, we used chloride sodium $(\mathrm{NaCl})$ because of its interesting chemical properties especially its high solubility. It was added homogeneously. The system is constantly stirred for about $10-15 \mathrm{~min}$. The dispersion has been transferred in a Petri dish and protected with a clean aluminum sheet; the acetic acid solvent was completely removed by natural evaporation (1 day).

4) Obtained samples have been then dried up at $60^{\circ} \mathrm{C}$ and the particles (salt or sucrose) were removed in distilled water. Immersing the sample in distilled water for at least $48 \mathrm{~h}$ washes out the salt; the water was refreshed twice every $6 \mathrm{~h}$ to favor the complete dissolution of the salt.

5) In the final step, the scaffolds were left to dry for $24 \mathrm{~h}$, and 154 SLUP scaffolds were obtained.

A range of composite scaffolds by salt leaching using powder has been elaborated and summarized in Table 1. 
Fig. 1 SLUP process

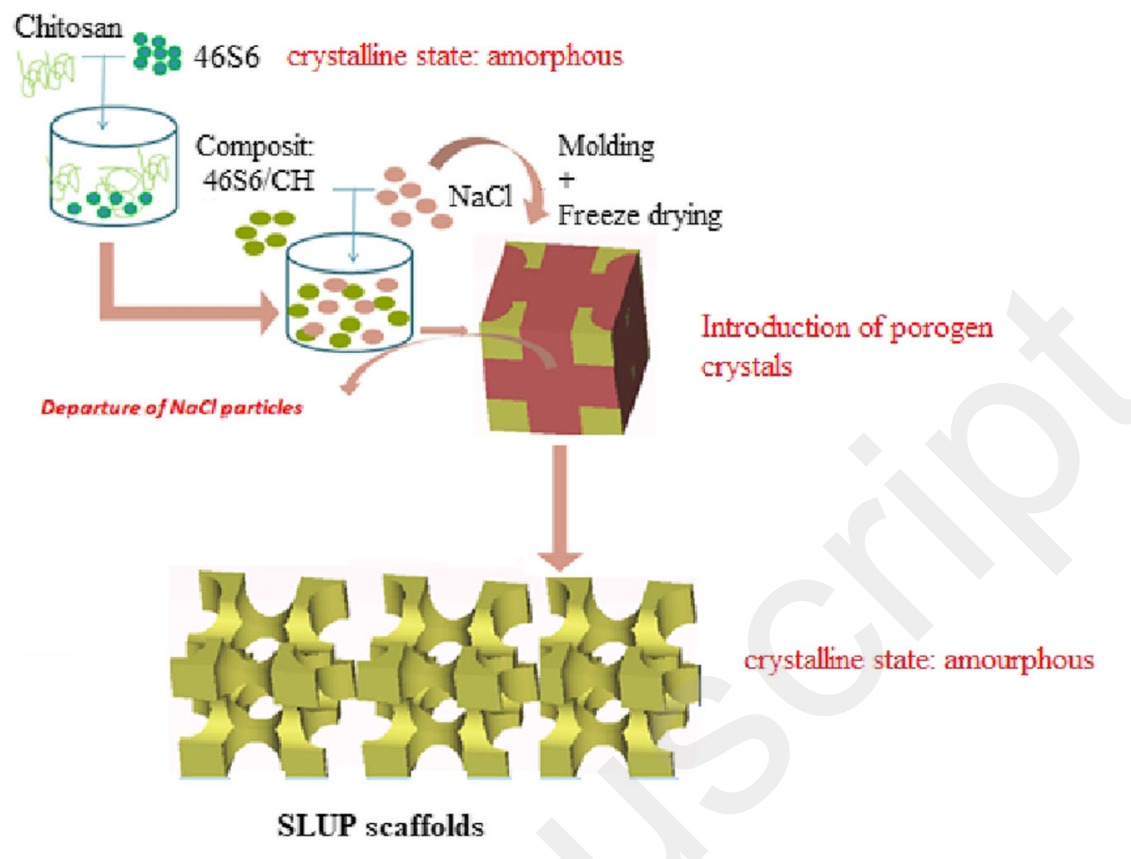

According to the technique and chitosan rate, they were simply called SLUPS29, SLUPS50, SLUPS71, and SLUPS90.

\section{Preparation of lyophilized scaffolds LS}

The same range was synthesized by using lyophilization process: The first step has consisted to dissolve chitosan powder, with a medium molecular weight, in acetic acid solution $1 \%$ $\mathrm{v} / \mathrm{v}$. The solution was stirred under magnetic stirring at room temperature during $24 \mathrm{~h}$ in order to dissolve all the chitosan powder. The final step is the preparation of four scaffolds having the same $\mathrm{CH}$ and $\mathrm{BG}$ ratio as those prepared by SLUP method: LS:29CH, LS:50CH, LS:71CH, and LS:90CH presenting different ratios chitosan/glass $(\mathrm{CH} / \mathrm{BG})$. The glass was added in the chitosan solution. The mixtures were homogenized for $24 \mathrm{~h}$ in an ultrasonic bath. The solutions were cast into well plates. They were frozen at $-20{ }^{\circ} \mathrm{C}$ all-night to freeze the core of the material and placed in a freeze-dryer at $0.65 \mathrm{mbar}$ at $-60{ }^{\circ} \mathrm{C}$ during $24 \mathrm{~h}$ to remove all solvents in samples. Obtained scaffolds were washed in a $\mathrm{NaOH}$ solution $0.4 \% \mathrm{w} / \mathrm{v}$ and distilled water to eliminate traces of acetic acid.

\section{Physicochemical characterization of scaffolds}

To verify that the synthesized material is an amorphous glass, its structure has been studied by using X-ray diffraction (XRD). XRD measurements were performed with a PAN analytical model operate at $40 \mathrm{kV}$ and $30 \mathrm{~mA}$ using $\mathrm{Cu} \mathrm{K} \alpha$ radiation. The detector was scanned over a range of $2 \theta$ angles from $5^{\circ}$ to $90^{\circ}$ at a step size of $0.026^{\circ}$ and well time of $40 \mathrm{~s}$ per step. The Fourier transform infrared spectroscopic analysis (FT-IR) was used to determine the functional groups composed the obtained scaffolds. A Bruker Equinox 55 spectrometer was employed for the FT-IR spectroscopy analysis. The samples of scaffolds powders were mixed with $\mathrm{KBr}$ powder and pressed into a disk suitable for FT-IR measurement. The FT-IR spectra were recorded from 4000 to $400 \mathrm{~cm}^{-1}$. The morphology of the scaffolds was observed using scanning electron microscopy (SEM) (Jeol JSM 6301). The flow of electrical charges at the surface is necessary for the SEM analysis. For that, samples have been metalized by gold-palladium layer (a few $\mu \mathrm{m}$ of thickness).

Specific surface area and pore size distribution of the samples have been calculated by using Brunauer-Emmett-Teller

Table 1 Chemical composition of scaffolds

\begin{tabular}{llllllll}
\hline Sample & $\begin{array}{l}\text { Solvant volume } \\
1 \%(\mathrm{ml})\end{array}$ & $\begin{array}{l}\text { Mass of } \\
\text { chitosan }(\mathrm{g})\end{array}$ & $\begin{array}{l}\text { Concentration of the } \\
\text { chitosan solution }(\%)\end{array}$ & $\begin{array}{l}\text { Mass of used } \\
\text { glass }(\mathrm{g})\end{array}$ & $\begin{array}{l}\text { \% by weight of chitosan } \\
\text { in composites }\end{array}$ & Composite notation & NaCl/Composite \\
\hline SLUP29 & 80 & 0.80 & 1 & 2.00 & 29 & $46 \mathrm{~S} 6: 29 \mathrm{CH}$ & 1 \\
SLUP50 & 140 & 1.40 & 1 & 1.40 & 50 & $46 \mathrm{~S} 6: 50 \mathrm{CH}$ & 1 \\
SLUP71 & 200 & 2.00 & 1 & 0.80 & 71 & $46 \mathrm{~S} 6: 71 \mathrm{CH}$ & 1 \\
SLUP90 & 252 & 2.52 & 1 & 0.28 & 90 & $46 \mathrm{~S} 6: 90 \mathrm{CH}$ & 1 \\
\hline
\end{tabular}



[32]

\begin{tabular}{lllllllll}
\cline { 2 - 7 } $\mathrm{t} 2.2$ & & $\mathrm{Na}^{+}$ & $\mathrm{K}^{+}$ & $\mathrm{Ca}^{2+}$ & $\mathrm{Mg}^{2+}$ & $\mathrm{Cl}^{-}$ & $\mathrm{HCO}_{3}^{-}$ & $\mathrm{HPO}_{4}^{2-}$ \\
\cline { 2 - 7 } $\mathrm{t} 2.3$ & $\mathrm{SBF}$ & 142 & 5 & 2.5 & 1.5 & 148.8 & 4.2 & 1 \\
$\mathrm{t} 2.4$ & Blood plasma & 142 & 5 & 2.5 & 1.5 & 103 & 27 & 1 \\
\cline { 2 - 7 }
\end{tabular}

The porogen was used with the aim of optimizing the pores network; the solid porogen agent spreads in the structure in a controlled manner. It makes it possible to have better control of the pore size, particularly access to large sizes and better control of the pore's organization. The porogenic agent chosen (in particulate form, preferably (quasi-spherical) may be preferentially removed to obtain the porous layer whose pores may have substantially the shape and size of this poreforming agent.

As depicted in Fig. 2, porosity appears in Fig. 2a just after salt-leaching out. The obtained images show that the composite before leaching (Fig. 2a) is characterized by a compact surface covered by a layer of porogen. After leaching (Fig. $2 b$ ), we clearly observe a radical change in the surface of the composite with the appearance of an organized porosity that occupies the entire surface of the composite. The efficiency of the process is directly related to the porogen.

\section{SEM}

Morphology of the surface and of the interconnectivity of the fabricated scaffolds is presented in Fig. 3. Porous structure was observed on both; lyophilized scaffolds (Fig. 3a) and SLUP scaffold (Fig. 3b) at BG:chitosan contents of 50:50. A regular porous structure was observed in SLUPS; however, that of LS was irregular.

From a morphological point of view, the porosity of SLUP scaffold is much greater than that of LS scaffolds. SEM images showed the influence of the salt particles on the pore size. It highlights the form and pore size uniformity. It shows the surface image and macrostructure of original salt-leaching scaffold with $\mathrm{NaCl}$ treatment. It demonstrates that pores create an interconnected network and are ideal for the vascularization. Therefore, the microstructure of the SLUP scaffolds is extremely promising since it is highly porous, with a welldeveloped network of interconnected pores.

This analysis aims also to observe the distribution and architecture of the pores and to understand the association between bioactive glass and chitosan matrix in a regular porosity. We have noticed from the SEM images that this phenomenon is very important in the SLUP scaffolds. Good interconnectivity of the global pores was observed, and the coexistence of orders in obtained pores was verified.

The pores and caves structure in each sample can be clearly observed; with the pore size of around $30 \mu \mathrm{m}$ sieving process in the SLUP scaffold (Fig. 3a) and heterogeneous pore size in the lyophilized scaffold as depicted in Fig. $3 \mathrm{~b}$.

Image of lyophilized scaffold (Fig. 3b) showed irregular pore structure and hole presence. There are no distinct and deep pores. The size and the shape of the pores were nonuniform, and the pores tended to be piled up pell-mell with each other. For tissue engineering applications, irregular structure is unfavorable for the cell migration and growth because of the 
Fig. 2 Images of SLUP scaffolds before (a) and after (b) the salt leaching using binocular microscopy
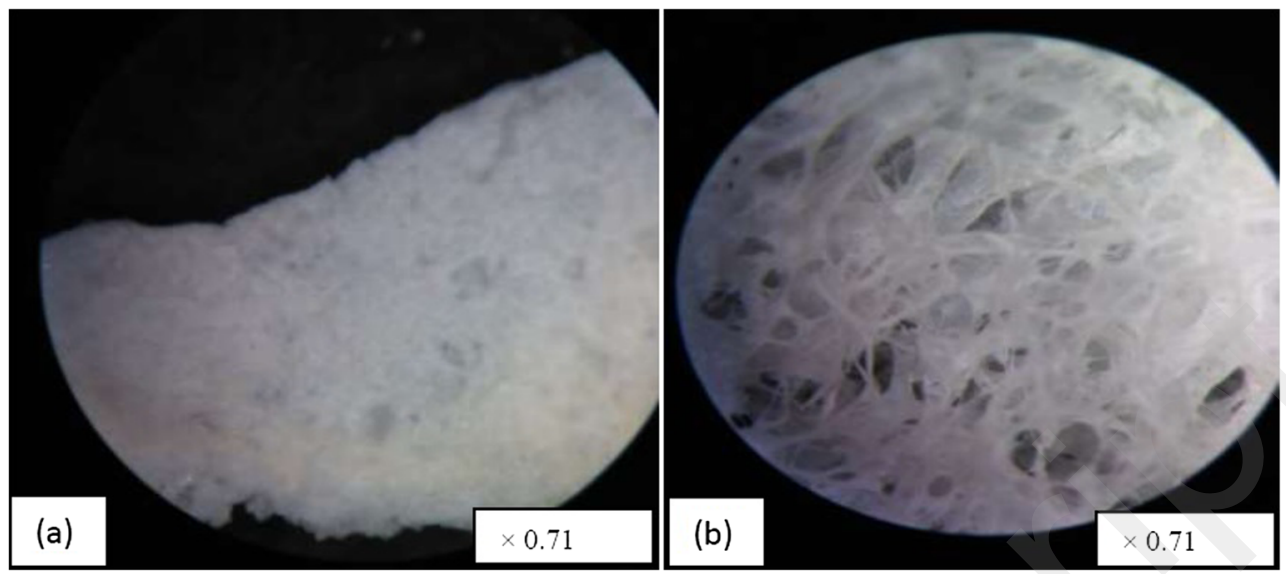

pore architecture wish going from the surface to interior of matter. However, the pore structure became more and more clear and integral with the increase of $\mathrm{NaCl}$ content. Especially, obvious honeycomb-like structure could be observed especially in the samples with higher $\mathrm{NaCl}(\mathrm{NaCl}$ : composite $=1$ ) as shown in Fig. 3a. Upon salt particles, the obtained results show a soft structure with regular pores. Before leaching, there is a lot of obvious configuration like oval-shaped salt powder, which is leached out. The picnometric measurements revealed that $90 \%$ of pore size corresponds to the particle size of $\mathrm{NaCl}$ used as porogen.
The salt particles spread to the bottom of the scaffold matrix creating a high porosity as shown in Fig. 4 . Therefore, the porosity of SLUP scaffold is higher than that of traditional scaffold. The porosity of the material is one of the key parameters successes in tissue engineering applications. Its pore volume (void volume inside), pore size, and specially the interconnection between pores have a major influence on the ability of the bone-implant vascularization and gradually biomineralization. They subsequently influence adhesion, cell migration, and tissue penetration within structures. It is therefore an important parameter for tissue engineering. Other studies have

Fig. 3 Morphology of the surface and of the interconnectivity of the fabricated scaffolds. a Lyophilized scaffolds; b SLUP scaffold

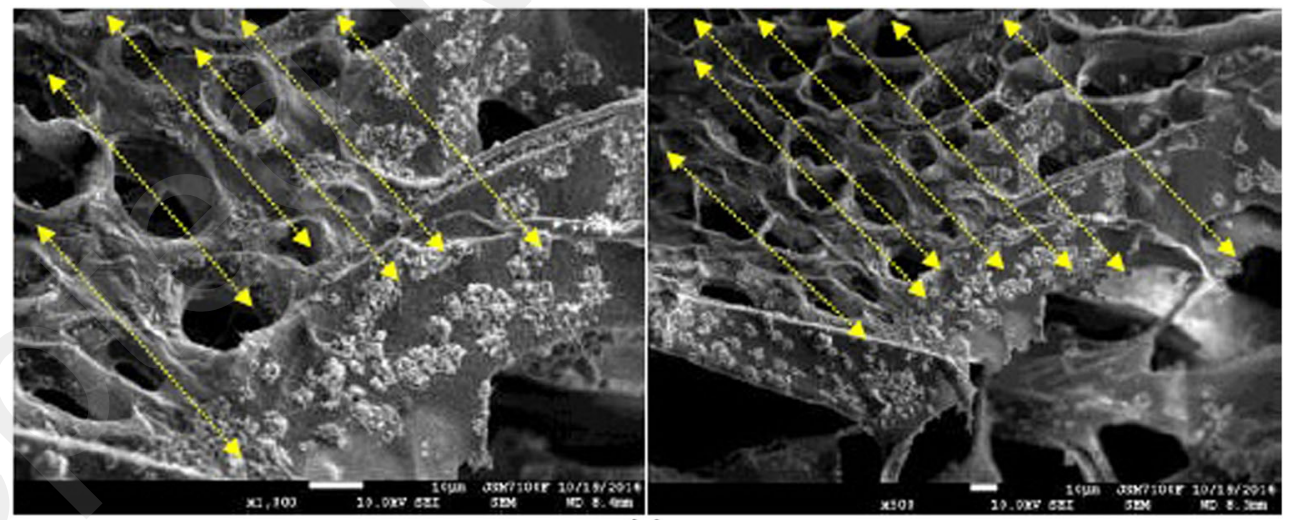
(a)

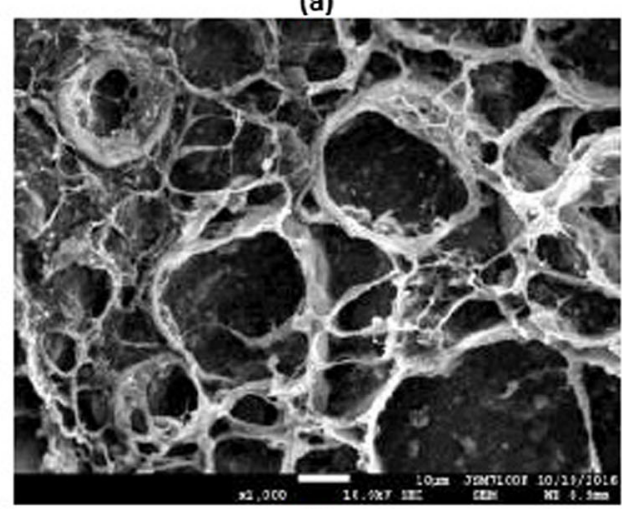

(b) 
Fig. 4 Salt particles spread to the bottom of the scaffold matrix creating a high porosity

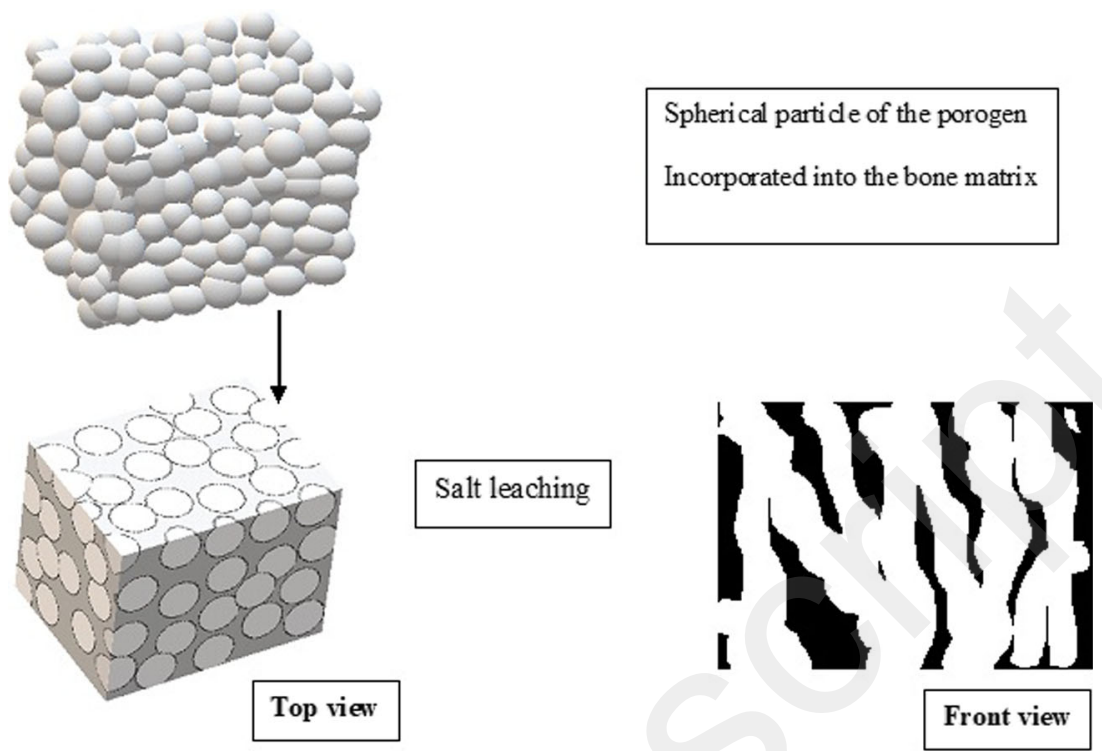

reported that the induced porogen on the composite matrix generates a regular porosity $[27,33]$.

\section{XRD and BET}

The obtained diffractograms are presented in Fig. 5. The 46S6-CH composite before the addition of progen presents a diffraction halo between 16 and $24\left(2 \theta^{\circ}\right)$ that we also observe on the diffractogram of chitosan alone. We also note the appearance of a halo at $30\left(2 \theta^{\circ}\right)$ which highlights interactions between bioactive and chitosan. After the addition of porogen, we notice the appearance of the peaks corresponding to $\mathrm{NaCl}$ (31.8 and $45.4\left(2 \theta^{\circ}\right)$ ), which disappear just after salt-leaching out. They assert that the crystalline structure of the scaffolds

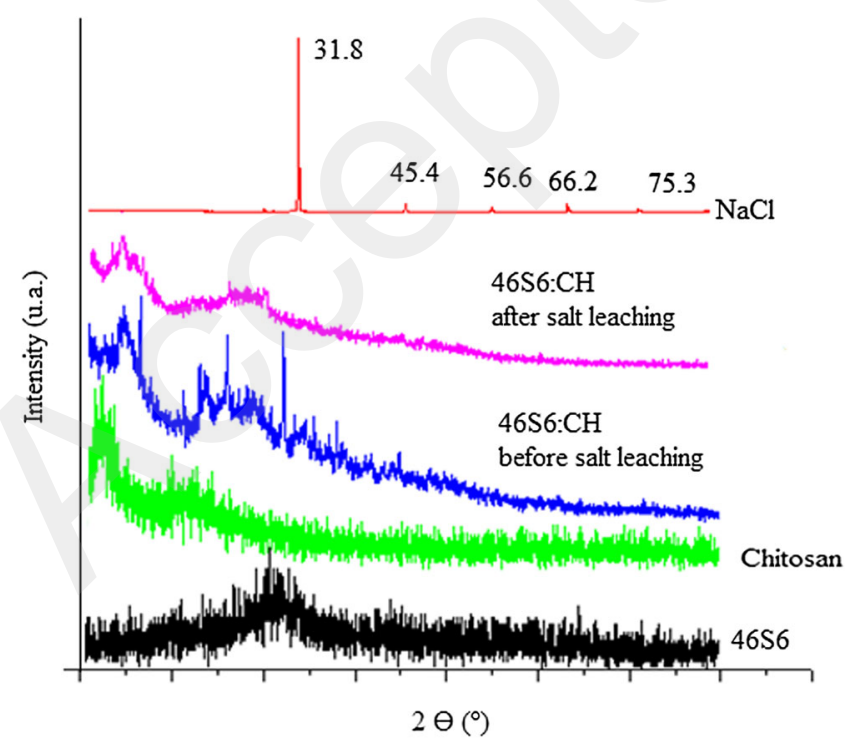

Fig. 5 Diffractograms after salt leaching retains its amorphous starting structure, which proves that the totality of porogen was leached out even that incorporated on the scaffolds structure leaving voids interconnected between them. After water leaching, the $\mathrm{NaCl}$ was dissolved in water and the peaks of this phase in the XRD pattern disappeared accordingly after salt-leaching out as shown in Fig. 1, and no streak attributed to $\mathrm{NaCl}$ was detected on the scaffold diffractogram. This result was also confirmed by EDS analysis as shown in Fig. 6, which shows the disappearance of the porogen within the matrix of the composite.

\section{Porosity calculation}

SLUP scaffolds possessed highest porosity (90\%) as presented in Fig. 7. The high porosity of a scaffold can provide benefits for cell growth and migration. We observe more that the $\mathrm{BG} / \mathrm{CH}$ ratio decreases towards a more porous structure. Table 3 presents the evolution of porosity rate according to the composition of our SLUP scaffolds and LS. Open porosity varies from 73 to $90 \%$ of SLUP when the open porosity rate of LS was too low and varies from 12 to $31 \%$.

Comparing SLUPS with LS, BET measures show an important evolution of pore volume in the case of SLUPS instead of LS as depicted in Fig. 8. In the case of LS, the pore volume varies between 3.8 and $6.5 \mathrm{~mm}^{3} \mathrm{~g}^{-1}$ depending on the $\mathrm{BG}: \mathrm{CH}$ ratio. However, it varies between 5 and 6 in the case of SLUP scaffolds.

This characteristic justifies more and more the advantages of the technique "SLUP" and allows us to understand the physical behavior at the interior of the scaffolds matrix. In fact, SLUP is pressure free; there was a definite space between the powder particles, and this space does not shrink while melting composite, which leads to create a large pore volume. 
Fig. 6 EDS analysis
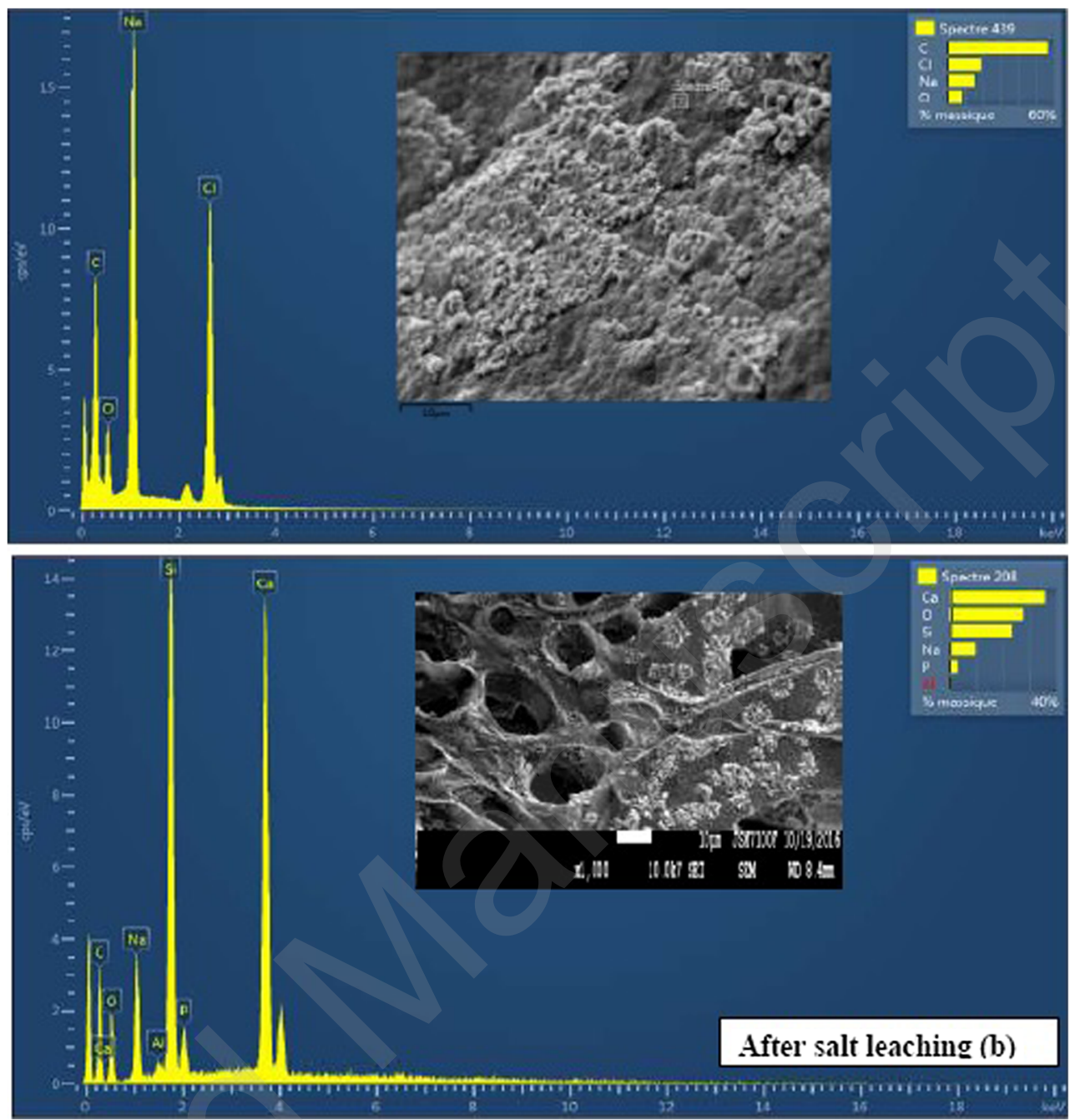

\section{Specific surface area}

The specific surface area represents the total area per $1 \mathrm{~g}$ of sample. It is therefore necessary to consider the entire surface of each particle, open porosity included. The physical

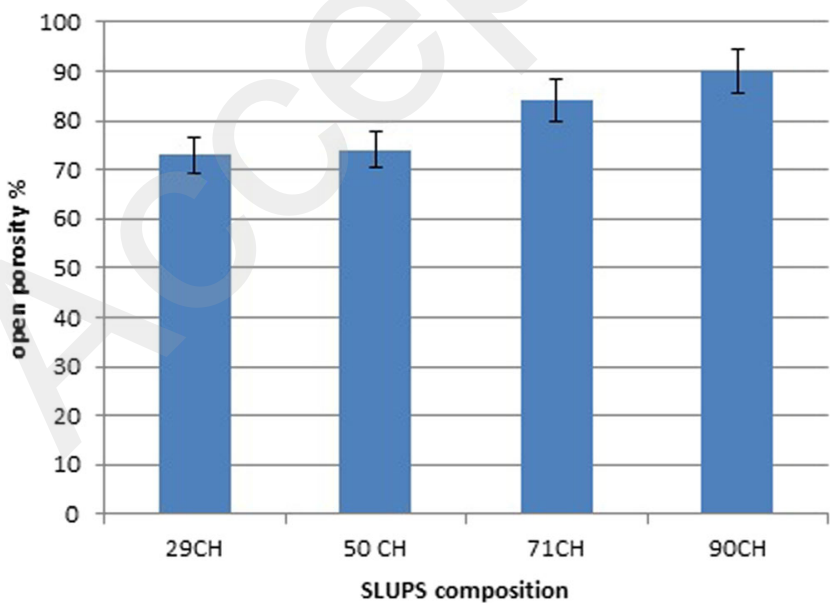

Fig. 7 SLUPS composition principle, recognized for the determination of the specific surface, is based on the adsorption of gas at low temperature. It allows a measurement without modification of the geometrical texture of the sample and determining the area of the entire surface of the powder particles, including the surface of the open pores accessible to the external gas molecules.

Figure 9 shows a progression of the specific surface area of SLUP scaffolds by increasing the chitosan rate in there, which varies between 20 and $37 \mathrm{~m}^{2} \mathrm{~g}^{-1}$. This increase is much more remarkable when applying the salt-leaching technique compared with the loyalty method, which showed a slight increase in a low specific surface area.

Table 3 Porosity rate according to the composition of SLUP scaffolds

\begin{tabular}{llll}
\hline Sample: SLUP & Porosity $\%$ & Sample LS & Porosity $\%$ \\
\hline SLUP29 & 73 & LS29 & 12 \\
SLUP50 & 75 & LS50 & 16 \\
SLUP71 & 95 & LS71 & 22 \\
SLUP90 & 90 & LS90 & 31 \\
\hline
\end{tabular}


Fig. 8 BET measures comparing SLUPS with LS

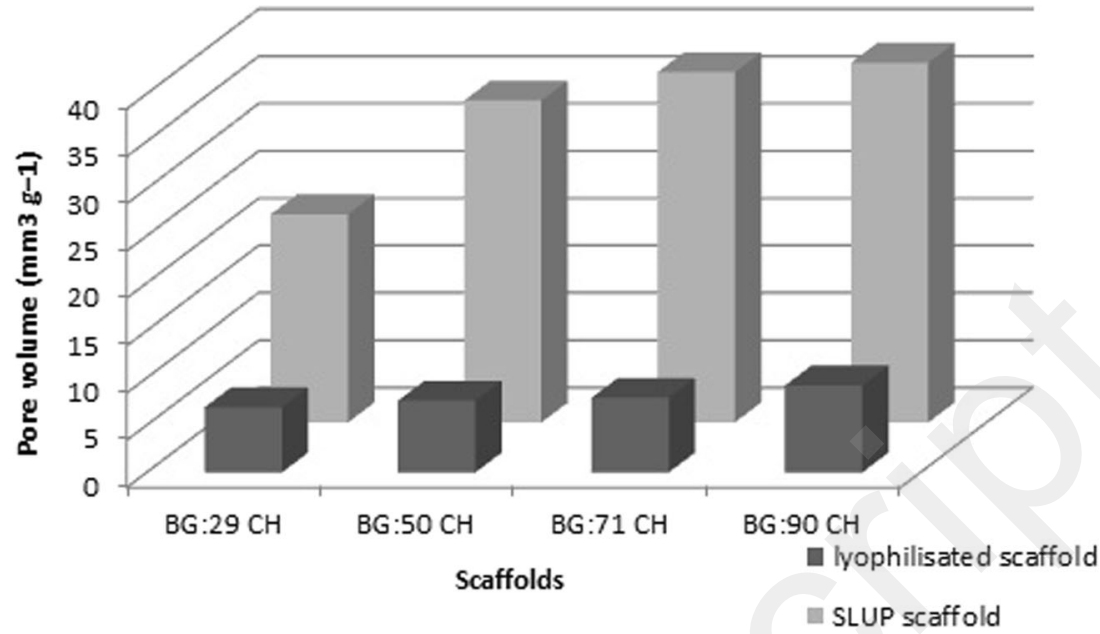

This increase is much more important when applying the SLUP technique compared with the conventional chemical method, which showed a slight increase in a low specific surface area.

\section{BET analysis nitrogen}

Porosity was evaluated by Brunauer-Emmet-Teller (BET) method using Micromeritics ASAP analyzer Isotherms of SLUP scaffolds as shown in Fig. 10.

All samples exhibited isotherms of type IV based on the IUPAC classification. According to the International Union of Pure and Applied Chemistry (IUPAC) classification, the obtained isotherms (Fig. 10) belong to type H3. The curves of adsorption and desorption form a hysteresis loop. The hysteresis cycle is due to the capillary condensation phenomenon characteristic of amesoporous material (pore diameter between $2 \mathrm{~nm}$ and less than $50 \mathrm{~nm}$ ). On each hysteresis cycle, shoulders, characteristic of several families of mesoporous materials, are observed at $\mathrm{P} / \mathrm{P} 0=0.5$.

\section{Pores size control}

In this process, we used porogen as a porosity control tool. This analysis was done to verify the hypothesis of the dependence of the pore size as well as the homogeneity of porosity on the particle size of the porogen. For this purpose, we have worked with a range of porogen varying each time the particle size. The pores have the same size as the porogen particles. The SEM photos of these composites clearly show the change in pore size from one composite to another relative to the change in pore size. We can deduce that pores take the same size of porogen particles as confirmed by SEM graphs (Fig. 11).

\section{Influence of porogen rates on the specific surface and porosity volume of scaffold SLUPS}

Using the proposed SLUP technique, the specific surface and porosity volume could be easily controlled via a simple procedure, as depicted in Fig. 12. It has been noticed
Fig. 9 Progression of the specific surface area of SLUP scaffolds by increasing the chitosan rate

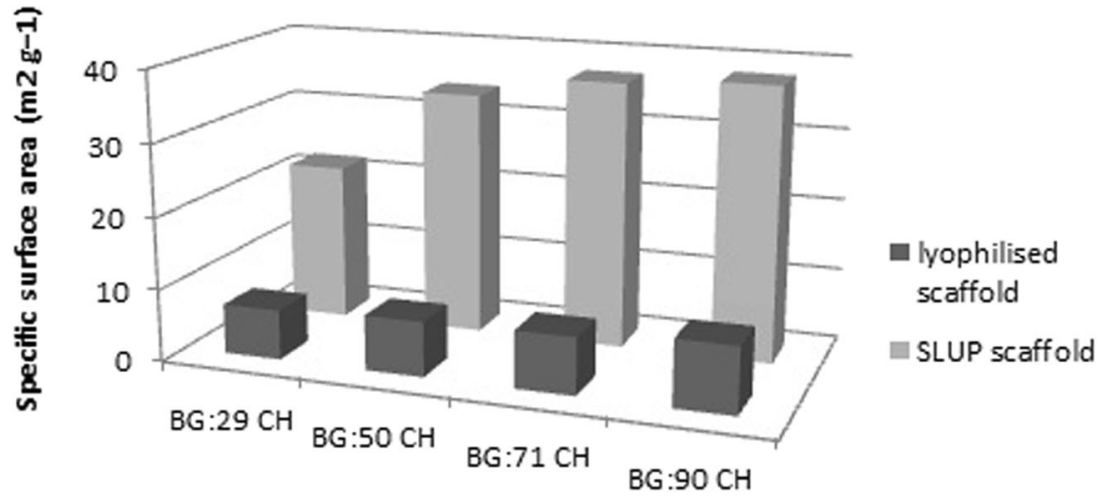

Scaffolds 

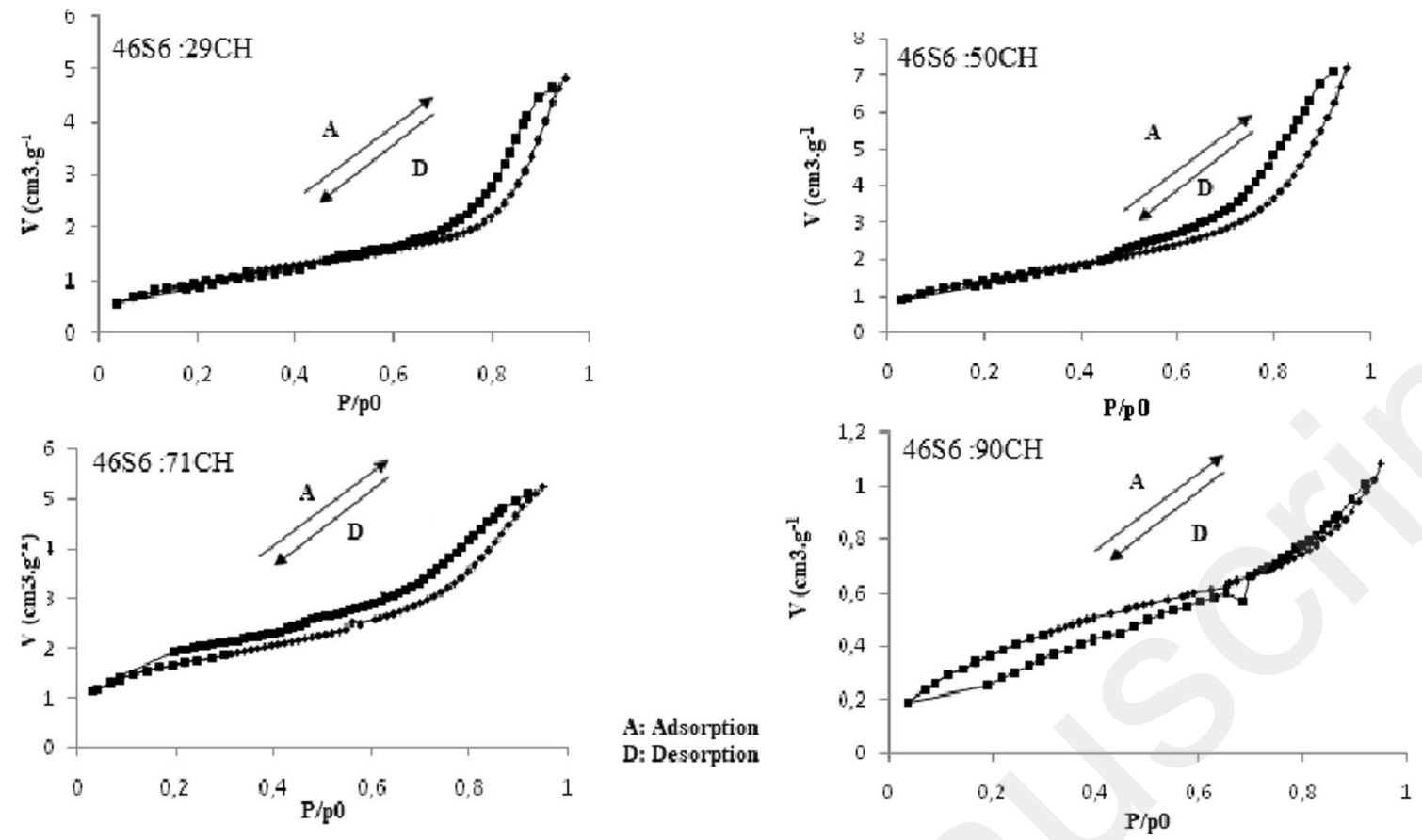

Fig. 10 Porosity evaluated by Brunauer-Emmet-Teller (BET) method using Micromeritics ASAP analyzer Isotherms of SLUP scaffolds

that the pore volume increases by increasing the rate of porogen in the composition of the scaffold (Fig. 12), which allows to control pore's volume and to have the pore volume of the requested pore.

\section{Kinetic of the chemical reactivity of SLUPS}

The XRD patterns of the glass after soaking in SBF for different periods confirm the formation of carbonated
Fig. 11 SEM graphs of parogen particles
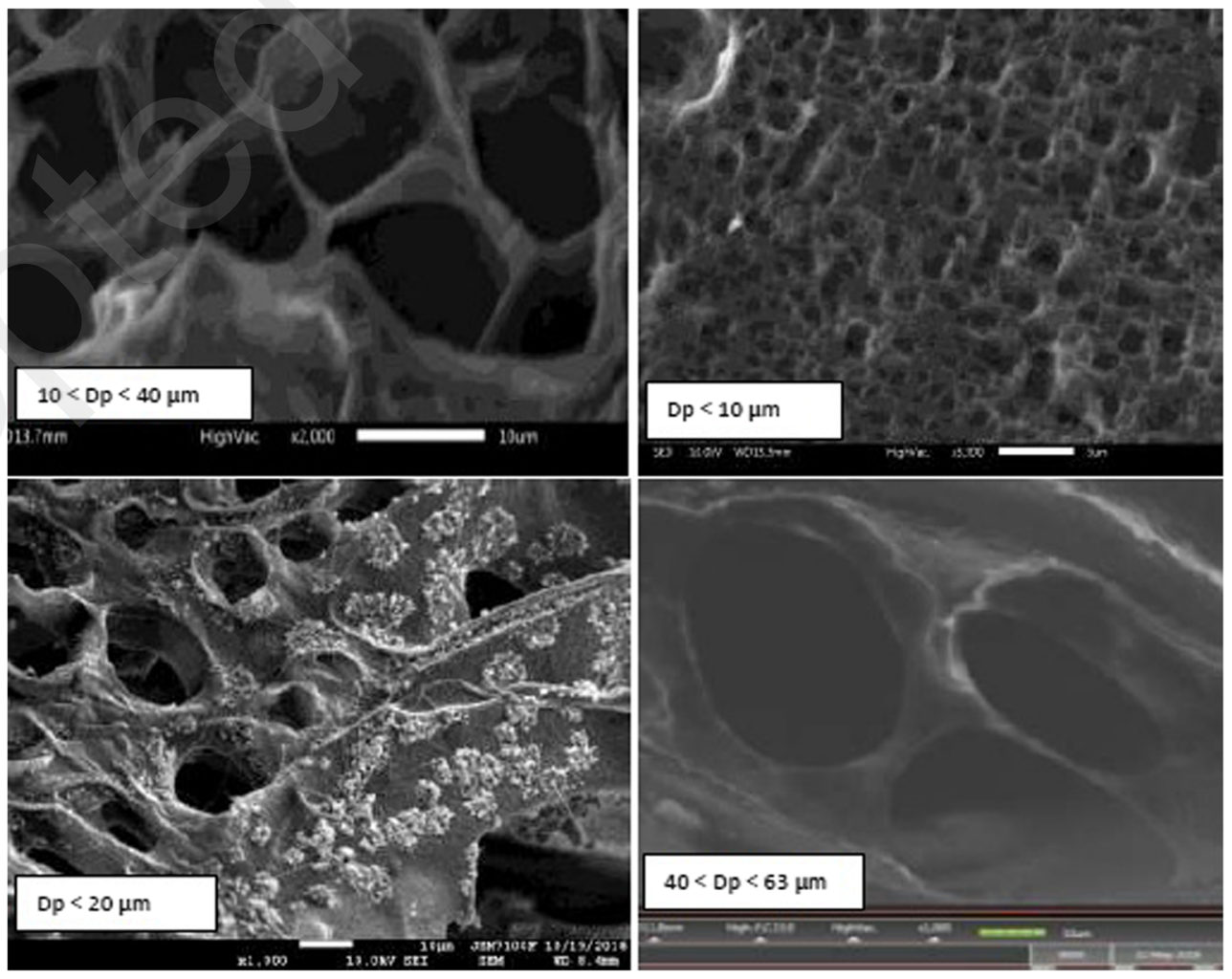
Fig. 12 Pore volume increases by increasing the rate of porogen in the composition of the scaffold

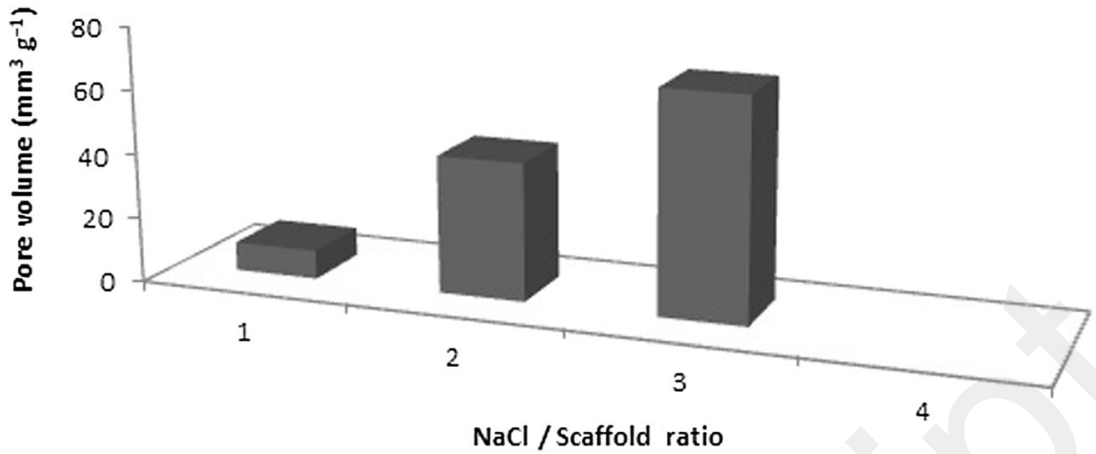

hydroxyapatite (HCA) on the surface of SLUPS. Figure 13 shows the XRD patterns for SLUPS 50 before and after soaking in SBF at different time intervals $(24,48$, and $72 \mathrm{~h})$. After $24 \mathrm{~h}$ of soaking in SFB solution, two characteristic peaks of hydroxyapatite at $25.80^{\circ}$ and $31.79^{\circ}$ were observed. The intensity of the peaks increases with increasing time of soaking to 3 days. These results highlight the high bioactivity of SLUP scaffolds.

\section{Porogen effects on the kinetic of the chemical reactivity}

Evolutions of silicon, calcium, and phosphorus concentrations in SBF, measured by ICP-OES, versus soaking time, are presented in Fig. 14. The evolution of the concentrations of all these elements followed a similar trend: strong evolution within the first 3 days. The concentration of silicon increased during the first $24 \mathrm{~h}$. At the same time, the calcium and phosphorus concentration decreased. The evolution of silicon concentration in SBF clearly indicated that a dissolution of the glass occurred during the first hour after soaking. This evolution is due to the high porosity of SLUP scaffold. The decrease of the calcium and phosphorous concentration indicated that there was a calcium and phosphorus uptake by the glass surface.

The effect of the presence of porogen on the reactivity of the SLUPS surface has been studied. A total of 50 SLUPS and $50 \mathrm{LS}$ were selected for testing in vitro. Evolution of silicon, calcium, and phosphorus concentrations in SBF, measured by ICP-OES versus soaking time, are presented on Fig. 14a-c, respectively.

For SLUPS, the Si concentration increases from 0 to $52 \mathrm{ppm}$ in the first $24 \mathrm{~h}$, while for the LS, the Si concentration increases to only $25 \mathrm{ppm}$. Therefore, the release of the silica and, consequently, the dissolution of SLUPS occur during $24 \mathrm{~h}$. The same applies to the calcium and phosphorus, their concentrations in SBF decrease after $24 \mathrm{~h}$ in the case of SLUPS than LS. For more information on evolution of calcium and phosphorus concentration in SBF, we have analyzed these concentrations for a short soaking time. After $24 \mathrm{~h}$, the concentration of calcium increases from 180 to $370 \mathrm{ppm}$ and of phosphorus from 75 to $65 \mathrm{ppm}$ during the first $24 \mathrm{~h}$. In conclusion, the presence of porogen affects fragility and porosity, which increases the ion exchanges and consequently the bioactivity improvement.
Fig. 13 XRD patterns for SLUPS 50 before and after soaking in $\mathrm{SBF}$ at different time intervals $(24,48$, and $72 \mathrm{~h})$

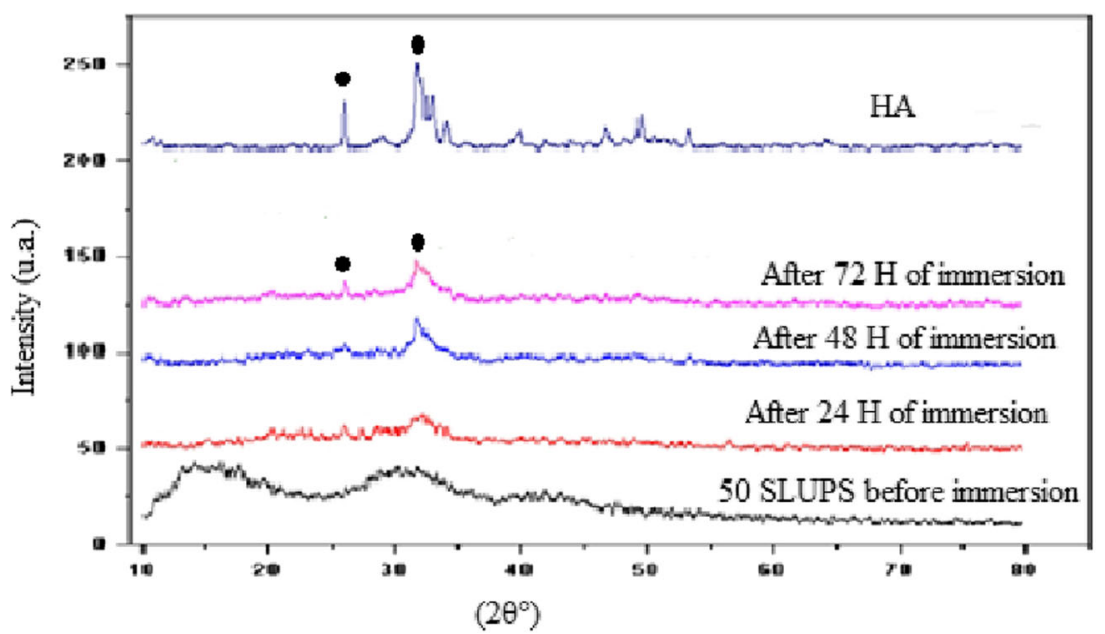



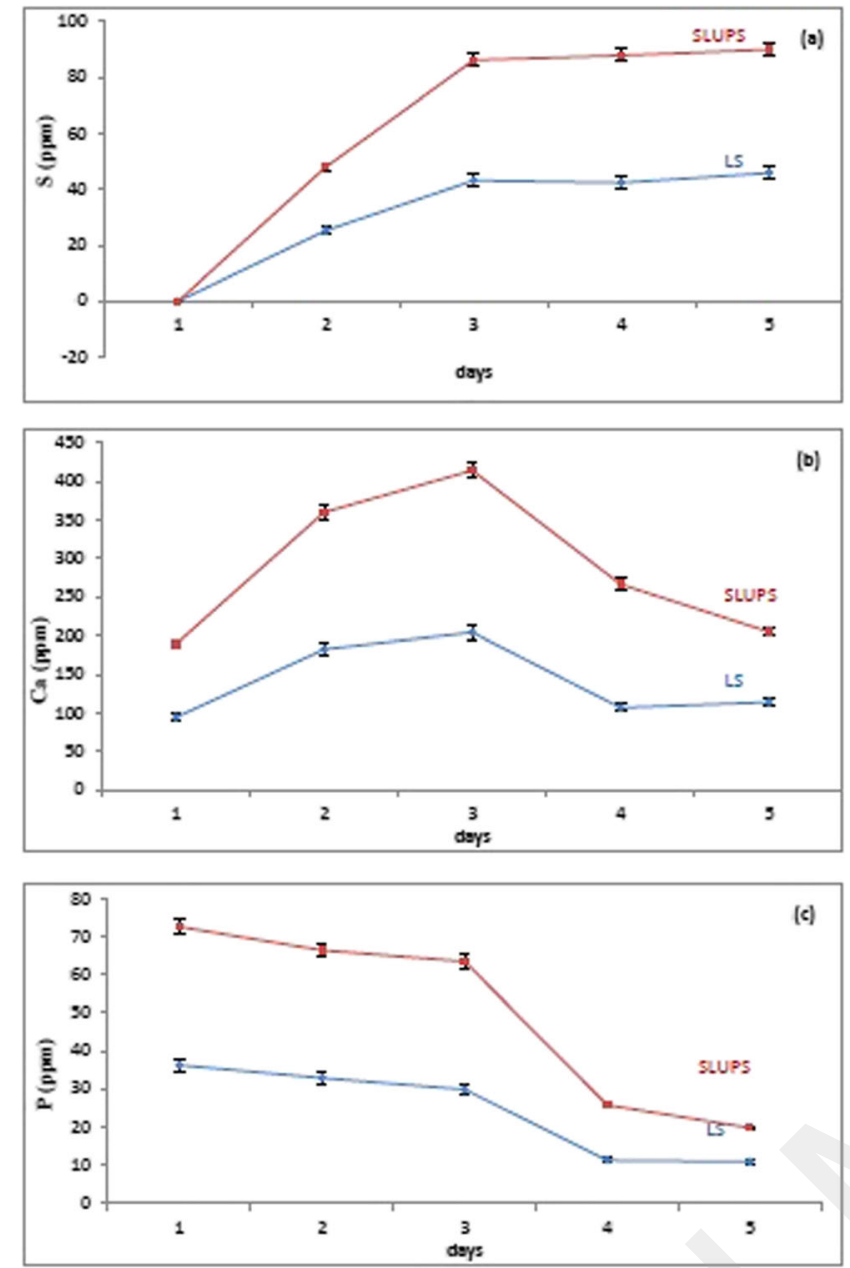

Fig. 14 Evolutions of silicon (a), calcium (b), and phosphorus (c) concentrations in SBF, measured by ICP-OES, versus soaking time

\section{Conclusion}

layer scaffold, with each layer having a different porosity and pore size, was fabricated. Thus, the SLUP (salt leaching using powder) technique may be a promising method for fabricating a scaffold in lab-scale experiments because when using SLUP, it is easy and facile to fabricate a well-interconnected scaffold with well-defined geometry.

Acknowledgments The authors gratefully acknowledge François Cheviré and Franck Tessier for the X-ray diffraction analysis, Odile Merdrignac-Conanec and Nathalie Herbert for BET measurements, and Francis GOUTTEFANGEAS, Loic JOANNY (CMEBA), and Cristophe Calers for scanning electron microscopy analysis, CMEBA.

\section{References}

1. Mezahi, F., Oudadesse, H., Harabi, A., Lucas-Girot, A., Le Gal, Y., Chaair, H., Cathelineau, G.: Dissolution kinetic and structural behavior of natural hydroxyapatite $v s$. thermal treatment, Comparison to synthetic hydroxyapatite. J. Therm. Anal. Calorim. 95(21), 546555 (2008)

2. Letaïef, N., Lucas-Girot, A., Oudadesse, H., Dorbez-Sridi, R., Boullay, P.: Investigation of the surfactant type effect on characteristics and bioactivity of new mesoporous bioactive glass in the ternary system $\mathrm{SiO}_{2}-\mathrm{CaO}-\mathrm{P}_{2} \mathrm{O}_{5}$ : structural, textural and reactivity studies. Microporous Mesoporous Mater. 195, 102-111 (2014)

3. Laurencin, C., Khan, Y., El-Amin, S.F.: Bone graft substitutes. Expert Rev. Med. Dev. 3(1), 49-57 (2006)

4. Ducheyne, P., Qui, Q.: Bioactive ceramics: the effect of surface reactivity on bone formation and bone cell function. Biomaterials. 20(23-24), 2287-2303 (1999)

5. Ilan, D.I., Ladd, A.L.: Bone graft substitutes. Oper. Tech. Plast. Reconstr. Surg. 9(4), 151-160 (2002)

6. Johnson, R.D., Todd, R.J., Arnold, F.H.: Multipoint binding in metal-affinity chromatography II. Effect of $\mathrm{pH}$ and imidazole on chromatographic retention of engineered histidine-containing cytochromes c. J. Chromatogr. A. 725(2), 225-235 (1996)

7. Nasrabadi, B., Mehrasa, M., Rafienia, M., Bonakdard, S., Behzada, T., Gavanjiea, S.: Porous starch/cellulose nanofibers composite prepared by salt leaching technique for tissue engineering. Carbohydr. Polym. 108, 232-238 (2014)

8. Zhuanga, P.Y., Li, Y.L., Fan, L., Lin, J., Hu, Q.L.: Modification of chitosan membrane with poly(vinyl alcohol) and biocompatibility evaluation. Int. J. Biol. Macromol. 50(3), 658-663 (2012)

9. Hutmacher, D.W.: Scaffolds in tissue engineering bone and cartilage. Biomaterials. 21(24), 2529-2543 (2000)

10. Liebschner, M.A.K., Wettergreen, M.A.: Optimization of bone scaffold engineering for load bearing applications. Topics in Tissue Engineering. 23, 345-362 (2003)

11. Rakovsky, A., Gotman, I., Rabkin, E., Gutmanas, E.Y.: Strong bioresorbable Ca phosphate-PLA nanocomposites with uniform phase distribution by attrition milling and high pressure consolidation. J. Mech. Behav. Biomed. Mater. 18, 37-46 (2013)

12. Kim, T.G., Chung, H.J., Park, T.G.: Macroporous and nanofibrous hyaluronic acid/collagen hybrid scaffold fabricated by concurrent electrospinning and de- position/leaching of salt particles. Acta Biomater. 6(4), 1611-1619 (2008)

13. Hollander, A.P., Hatton, P.V.: Biopolymer Methods in Tissue Engineering. Methods Mol. Biol. 238, (2004)

14. Cho, Y.S., Hong, N.M., Kim, S.Y., Lee, S.J., Lee, J.H., Kim, Y., Cho, Y.S.: Fabrication of dual-pore scaffolds using SLUP (salt leaching using powder) and WNM (wire-network molding) techniques. Mater. Sci. Eng. 45, 546-555 (2014)

\section{$485 \mathrm{Q} 9$}


15. Park, H.J., Lee, O.J., Lee, M.C., Moon, B.M., Ju, H.W., Jm, L., Kim, J.H., Kim, D.W., Park, C.H.: Fabrication of 3D porous silk scaffolds by particulate (salt/sucrose)leaching for bone tissue reconstruction. Int. J. Biol. Macromol. 78, 215-223 (2015)

16. Cannillo, V., Chiellini, F., Fabbri, P., Sola, A.: Production of Bioglass ${ }^{\circledR}$ 45S5-polycaprolactone composite scaffolds via saltleaching. Compos. Struct. 92(8), 1823-1832 (2010)

17. Ezequiel, C.-J.S., Edel Barbosa-Stancioli, F., AlexandraMansur, A.P., Wander Vasconcelos, L., HermanMansur, H.: Preparation and characterization of chitosan/poly(vinyl alcohol) chemically crosslinked blends for biomedical applications. Carbohydr. Polym. 76(3), 472-481 (2009)

18. Kamoun, E.A., Kenawy, E.S., Tamer, M.T., El-Meligy, A.M., MohyEldin, S.M.: Poly (vinyl alcohol)-alginate physically crosslinked hydrogel membranes for wound dressing applications: characterization and bio-evaluation. Arab. J. Chem. 8(1), 38-47 (2015)

19. Yu, S.H., Tsai, M.L., Lin, B.X., Lin, C.W., Mi, F.L.: Tea catechinscross-linked methyl- cellulose active films for inhibition of light irradiation and lipid peroxidation induced $\beta$-carotene degradation. Food Hydrocoll. 44, 491-505 (2015)

20. Kanimozhi, K., Khaleel Basha, S., Sugantha Kumari, V.: Processing and characterization of chitosan/PVA and methylcellulose porous scaffolds for tissue engineering. Mater. Sci. Eng. 61(1), 484-491 (2016)

21. Trong, M., Chia-Fong, K., Wen-Yen, C., Ching, A.: Preparation and characterization of chitosan-g-poly (vinyl alcohol)/poly(vinyl alcohol) blends used for the evaluation of blood-contacting compatibility. Carbohydr. Polym. 63(3), 331-339 (2006)

22. Collins, M.N., Colin, B.: Hyaluronic acid based scaffolds for tissue engineering. Carbohydr. Polym. 92(2), 1262-1279 (2013)

23. Seitz, H., Rieder, W., Irsen, S., Leukers, B., Tille, C.: Threedimensional printing of porous ceramic scaffolds for bone tissue engineering. Biomed. Mater. Res. 74(2), 782-788 (2005)

24. Wers, E., Oudadesse, H., Lefeuvre, B., Merdrignac-Conanec, O., Barroug, A.: Evaluation of the kinetic and relaxation time of gentamicin sulfate released from hybrid biomaterial Bioglass-chitosan scaffolds. Appl. Surf. Sci. 353, 200-208 (2015)
25. Son, J., Kim, G.: Three-dimensional plotter technology for fabricating polymeric scaffolds with micro-grooved surfaces. Biomater. Sci. Polym. 20(14), 2089-2101 (2009)

26. Yong, S., Myoung, W., So-Youn, K., Seung, J., Jun, H., Young, Y., Young, S.: Fabrication of dual-pore scaffolds using SLUP (salt leaching usingpowder) and WNM (wire-network molding). Techniques Materials Science and Engineering C. 45, 546-555 (2014)

27. Mehran, M., Mojtaba, N.: HA/nylon 6,6 porous scaffolds fabricated by salt-leaching/solvent casting technique: effect of nano-sized filler content on scaffold properties. Int. J. Nanomedicine. 6, 16511659 (2011)

28. Yang, D., Yu, K., Ai, Y., Zhen, H., Nie, J., Kennedy, J.E.: The mineralization of electrospun chitosan/poly(vinyl alcohol) nanofibrous membranes. Carbohydr. Polym. 84(3), 990-996 (2011)

29. Qi, X., Hu, X., Wei, W., Yu, H., Li, J., Zhang, J., Dong, W.: Investigation of Salecan/poly(vinyl alcohol) hydrogels prepared by freeze/thaw method. Carbohydr. Polym. 118, 60-69 (2015)

30. Wers, E., Oudadesse, H.: Thermal behaviour and excess entropy of bioactive glasses and Zn-doped glasses. J. Therm. Anal. Calorim. 115(3), 2137-2144 (2014)

31. Oudadesse, H., Wers, E., Bui, X.V., Roiland, C., Bureau, B., Akhiyat, I., Mostafa, A., Chaair, H., Benhayoune, H., Fauré, J., Pellen-Mussi, P.: Chitosan effects on glass matrices evaluated by biomaterial, MAS-NMR and biological investigations. Korean J. Chem. Eng. 30(9), 1775-1783 (2013)

32. Kokubo, T., Kushitani, H., Sakka, S., Kitsugi, T., Yamamuro, T.: Solutions able to reproduce in vivo surface-structure changes in bioactive glass ceramic A-W. J. Biomed. Mater. Res. 24(6), 721734 (1990)

33. Yong, S.C., Beom-Su, K., Hyung-Keun, Y., Young-Sam, C.: A novel technique for scaffold fabrication: SLUP (salt leaching using powder)? Curr. Appl. Phys. 14(3), 371-377 (2014)

Publisher's note Springer Nature remains neutral with regard to jurisdictional claims in published maps and institutional affiliations. 